\title{
THE HYDROLYSIS OF AGRO-INDUSTRIAL RESIDUES BY HOLOCELLULOSE-DEGRADING ENZYMES
}

\author{
Leonora Rios de Souza Moreira*, Gaspar Virgilio Ferreira, Sheila Sousa Thurler Santos, Ana Paula Souza Ribeiro, Félix \\ Gonçalves Siqueira, Edivaldo Ximenes Ferreira Filho
}

Laboratório de Enzimologia, Departamento de Biologia Celular, Universidade de Brasília, Brasília, DF, Brasil.

Submitted: March 31, 2011; Approved: January 16, 2012.

\begin{abstract}
Holocellulose structures from agro-industrial residues rely on main and side chain attacking enzymes with different specificities for complete hydrolysis. Combinations of crude enzymatic extracts from different fungal species, including Aspergillus terreus, Aspergillus oryzae, Aspergillus niger and Trichoderma longibrachiatum, were applied to sugar cane bagasse, banana stem and dirty cotton residue to investigate the hydrolysis of holocellulose structures. A. terreus and A. oryzae were the best producers of FPase and xylanase activities. A combination of $A$. terreus and $A$. oryzae extracts in a $50 \%$ proportion provided optimal hydrolysis of dirty cotton residue and banana stem. For the hydrolysis of sugar cane bagasse, the best results were obtained with samples only containing $A$. terreus crude extract.
\end{abstract}

Key words: agricultural waste, enzymatic mixtures, hydrolysis.

\section{INTRODUCTION}

Agro-industrial residues are available for exploitation as sources of fuel, food and chemical feedstocks (12). Agroindustrial residues consist basically of lignocellulosic material containing mainly cellulose (40-50\%), hemicellulose (30$40 \%)$, lignin $(8-10 \%)$ and a lower percentage of pectin. $(3,15)$. The use of agro-industrial residues as raw materials decreases the impact on the environment because it reuses these subproducts, reducing their accumulation in the environment and adding economic value to the waste. The production of ethanol from agro-industrial residues is a good alternative for improving energy availability. In recent years, there has been an increasing trend towards more efficient utilization of agroindustrial residues for different applications, including biofuel production (12). In addition, these agro-industrial residues can be used as a carbon source for the production of enzymes, especially holocellulases, by filamentous fungi. A broad range of hydrolytic enzymes are necessary for the degradation of the carbohydrate portion of lignocellulose (holocellulose) (1, 8, 14). Within this group of enzymes, xylanase, mannanase, polygalacturonase, endoglucanase and exoglucanase have important roles in the hydrolysis of holocellulose $(10,13)$.

The procedures to optimize the production of fungal holocellulases require only an inexpensive carbon source (13). Here, we investigate the potential use of dirty cotton residue (DCR), sugar cane bagasse (SCB) and banana stem residues (BS) as an inexpensive source of carbon. DCR is the fraction collected from the cotton spinning and yarn forming textile industries that is composed of very short fibers, husks and

*Corresponding Author. Mailing address: Laboratory of Enzymology, Department of Cellular Biology, University of Brasília, Brasília, DF, CEP 70910 900, Brazil.; E-mail: leonorarsm@gmail.com 
other dark matter. BS, the grain stalk that supports the banana fruit, is normally discarded from the "packing houses" or delivering centers after harvesting the fruit because it is considered waste due to the great volume generated (10). SCB is the largest Brazilian agro-industrial waste, amounting to approximately $217-380 \times 10^{6}$ tons per year $(5,6)$. The bagasse piles have low economic value and represent an environmental problem due to the risk of spontaneous combustion. This study will investigate the quantity of reducing sugars liberated in the hydrolysis of SCB, DCR and BS using different combinations of enzymatic extracts from filamentous fungi.

\section{MATERIALS AND METHODS}

\section{Organisms and enzyme production}

The fungi (Aspergillus flavus, Aspergillus niger, Aspergillus oryzae, Aspergillus terreus, Emericela nidulans, Monilia sp., Penicillium corylophilum and Trichoderma longibrachiatum) were obtained from the fungus culture collection of the Enzymology Laboratory, University of Brasília, Brazil, and maintained in PDA medium (2.0\% potato broth, $2.0 \%$ dextrose and $2.0 \%$ agar). An aliquot $(2.5 \mathrm{~mL})$ of a spore suspension $\left(10^{8}\right.$ spores $\left./ \mathrm{mL}\right)$ was inoculated in Erlenmeyer flasks containing $500 \mathrm{~mL}$ of liquid medium $(0.7 \%$ $\mathrm{KH}_{2} \mathrm{PO}_{4}, \quad 0.2 \% \quad \mathrm{~K}_{2} \mathrm{HPO}_{4}, \quad 0.05 \% \quad \mathrm{MgSO}_{4} \cdot 7 \mathrm{H}_{2} \mathrm{O}, \quad 0.01 \%$ $\left(\mathrm{NH}_{4}\right)_{2} \mathrm{SO}_{4}$, and $0.06 \%$ yeast extract) at $\mathrm{pH} 7.0$ with $1.0 \%(\mathrm{w} / \mathrm{v})$ sugar cane bagasse or dirty cotton residue as the carbon source. Fungi were grown for eight days at $28^{\circ} \mathrm{C}$ under agitation at 100 rpm. The resulting supernatants, hereafter called crude extracts, were used for the determination of holocellulose-degrading enzyme activities and extracellular protein concentrations.

\section{Substrates}

Xylan preparation was carried out as described elsewhere (12). The filter paper activity (FPase) assay was carried out with a strip of paper of $1 \times 6 \mathrm{~cm}$, Whatman number 1 .

\section{Residue Pretreatment}

SCB, BS and DCR were thoroughly washed with tap water and autoclaved at $121^{\circ} \mathrm{C}$ for $2 \mathrm{~h}$. After autoclaving, they were dried at $65^{\circ} \mathrm{C}$ for $48 \mathrm{~h}$ and ground to form a homogeneous blend. A fine powder was obtained and used as a substrate for enzymatic hydrolysis experiments.

\section{Enzyme assays}

Xylanase activity was determined by mixing $50 \mu \mathrm{L}$ of enzyme sample with $100 \mu \mathrm{L}$ of $1 \% \mathrm{w} / \mathrm{v}$ substrate (oat spelt xylan) at $50^{\circ} \mathrm{C}$ for $30 \mathrm{~min}$. FPase activity (9) was determined using $150 \mu \mathrm{L}$ of enzyme with filter paper (Whatman $\mathrm{N}^{\circ} 1$ ) as a substrate at $50^{\circ} \mathrm{C}$ for $1 \mathrm{~h}$. The amount of reducing sugar released was measured using acid 3,5 dinitrosalicylic acid (DNS) (10). Activity was expressed as $\mu$ mol reducing sugar formed per min per liter of enzyme solution, or IU/L. Glucose and xylose were used as standards. Protein concentration was measured by Bradford assay (2) using bovine serum albumin as the standard. Glucose content was measured by the glucose oxidase method (16)

\section{Hydrolysis Assays}

The degradation of agro-industrial residues by holocellulose-degrading enzyme crude extracts was determined by quantifying the reducing sugars that were released during the BS, SCB and DCR residue breakdown. The degradation of agro-industrial residues was determined by incubating different proportions $(30 \%-70 \%, 50 \%-50 \%$ and $70 \%-30 \%)$ of crude enzyme extracts named combinations $\mathrm{A}, \mathrm{B}$ and $\mathrm{C}$, respectively (comb $\mathrm{A}, \mathrm{B}$ and $\mathrm{C}$ ). The crude extracts from $A$. terreus, $A$. oryzae and $A$. niger were obtained from growth cultures containing $\mathrm{SCB}$, while the crude extract from $T$. longibrachiatum was from a growth culture containing DCR. Hydrolysis of SCB, DCR and BS was performed as follows: 10 $\mathrm{mL}$ of sodium acetate buffer ( $50 \mathrm{mM}, \mathrm{pH} 5.0$ ) was added to 0.5 $\mathrm{g}$ of pretreated substrate in $125 \mathrm{~mL}$ Erlenmeyer flasks. The mixture was then autoclaved at $121^{\circ} \mathrm{C}$ for $1 \mathrm{~h}$, and the contents of the flasks were incubated with $10 \mathrm{~mL}$ of enzyme solutions for $168 \mathrm{~h}$ at $50^{\circ} \mathrm{C}$ and $120 \mathrm{rpm}$. At various time points, aliquots $(2 \mathrm{~mL})$ were withdrawn to quantify reducing sugars released 
and glucose concentration. All experiments were performed in triplicate, and the data are reported as the average of those experiments, with the standard deviations indicated.

\section{Statistical Analysis}

The effect of different mixtures were statistically tested with the program PAST (Palaentological Statistics) (4), available in http://folk.uio.no/ohammer/past/. Data were submitted to normality test Shapiro-Wilk and than, One Way analysis of variance (ANOVA) and Tukey's Parwise Comparisons, with significance $\mathrm{P}<0.05$.

\section{RESULTS AND DISCUSSION}

In this study, fungi were grown in liquid cultures supplemented with SCB or DCR. Crude extracts from $A$. niger, A. oryzae, A. terreus, E. nidulans, Monilia sp., P. corylophilum and $T$. longibrachiatum were prepared to investigate their ability to degrade lignocellulosic substrates. Previous research (13) has shown that SCB, DCR and BS represent a rich source of lignocellulose. Bromatological analysis revealed that DCR was found to be particularly rich in cellulose, followed by BS and SCB. The highest hemicellulose contents were present in
BS and SCB. The lowest level of lignin was detected in SCB, while BS contained the highest lignin content. All crude extracts were screened for the production of holocellulosedegrading enzyme activities ( $\beta$-xylanase, $\beta$-mannanase, pectinase, $\beta$-glucosidase, avicelase, FPase and CMCase). Although fungal growth was abundant on both carbon sources, there were differences in the production of holocellulosedegrading enzyme activities (data not shown). Compared to the other fungi, A. terreus and $A$. oryzae were responsible for the greatest production of holocellulose-degrading enzymes (13).

Combinations of two crude extract samples (286 mixtures) were tested for xylanase and FPase activities and selected for hydrolysis experiments. Combination $\mathrm{B}$ of $A$. terreus crude extract grown on SCB and DCR exhibited the highest yield of FPase activity, followed by combination $\mathrm{B}$ of $A$. terreus and Monilia sp. (Table 1). The best yield of FPase activity was obtained from $A$. terreus crude extract grown on SCB, which also has low protein content, while combination B of the $A$. niger and E. nidulans crude extracts was the most active, with a $25 \%$ increase in xylanolytic activity (Table 2 ). Combination B of $A$. niger and E. nidulans showed the highest protein content.

Table 1. Crude extract combinations with higher FPase activity and correspondent protein quantification.

\begin{tabular}{cccc}
\hline Combinations & $\begin{array}{c}\text { FPase activity } \\
(\mathbf{I U} / \mathbf{m L})\end{array}$ & \pm SD & $\begin{array}{c}\text { Protein Concentration } \\
\boldsymbol{\mu g} / \mathbf{m L}\end{array}$ \\
\hline $\mathrm{At}^{1}$ & 0.507 & 0.001 & 5.50 \\
$\mathrm{At}^{1} / \mathrm{At}^{2}$ (Comb. B) & 0.371 & 0.005 & 27.79 \\
$\mathrm{At}^{1} / \mathrm{Mo}^{1}$ (Comb. B) & 0.322 & 0.020 & 24.56 \\
$\mathrm{Ao}^{1} / \mathrm{Tl}^{1}$ (Comb. A) & 0.318 & 0.004 & 35.22 \\
$\mathrm{Ao}^{1} / \mathrm{Tl}^{1}$ (Comb. B) & 0.312 & 0.015 & 46.05 \\
$\mathrm{At}^{1} / \mathrm{At}^{2}$ (Comb. A) & 0.294 & 0.010 & 33.60 \\
$\mathrm{At}^{1} / \mathrm{Af}^{1}$ (Comb. A) & 0,284 & 0.011 & 53.73 \\
$\mathrm{Ao}^{1} / \mathrm{Af}^{1}$ (Comb. A) & 0.284 & 0.011 & 50.60 \\
$\mathrm{Ao}^{1} / \mathrm{Ao}^{2}$ (Comb. A) & 0.278 & 0.007 & 63.24 \\
$\mathrm{Ao}^{1} / \mathrm{Mo}^{2}$ (Comb. A) & 0.275 & 0.015 & 20.24 \\
\hline
\end{tabular}

1- Crude extracts from the growth on sugar cane bagasse, ${ }^{2}$ - Crude extracts from the growth on dirty cotton residue. At: A. terreus; Mo: Monilia sp.; Ao: A. oryzae; Tl: T. longibrachiatum; Af: A. flavus. 
Table 2. Crude extract combinations with higher xylanase activity and correspondent protein quantification.

\begin{tabular}{lccc}
\hline \multicolumn{1}{c}{ Combinations } & $\begin{array}{c}\text { Xylanase activity } \\
(\mathbf{I U} / \mathbf{m L})\end{array}$ & \pm SD & $\begin{array}{c}\text { Protein Concentration } \\
(\boldsymbol{\mu g} / \mathbf{m L})\end{array}$ \\
\hline $\mathrm{An}^{1} / \mathrm{En}^{2}(\mathrm{Comb} . \mathrm{B})$ & 0.978 & 0.013 & 94.16 \\
$\mathrm{Af}^{1} / \mathrm{Mo}^{1}$ (Comb. B) & 0.778 & 0.015 & 74.03 \\
$\mathrm{An}^{1} / \mathrm{En}^{2}$ (Comb. A) & 0.756 & 0.010 & 42.87 \\
$\mathrm{Af}^{1} / \mathrm{Mo}^{1}$ (Comb. C) & 0.736 & 0.012 & 58.09 \\
$\mathrm{Af}^{2} / \mathrm{En}^{1}$ (Comb. C) & 0.733 & 0.015 & 55.11 \\
$\mathrm{Ao}^{1} / \mathrm{An}^{1}$ (Comb. A) & 0.720 & 0.011 & 51.69 \\
$\mathrm{Af}^{2} / \mathrm{An}^{1}$ (Comb. B) & 0.716 & 0.020 & 90.47 \\
$\mathrm{Af}^{2} / \mathrm{An}^{1}$ (Comb. C) & 0.703 & 0.013 & 86.13 \\
$\mathrm{Ao}^{1} / \mathrm{An}^{1}$ (Comb. B) & 0.702 & 0.008 & 76.35 \\
$\mathrm{An}^{1} / \mathrm{En}^{1}$ (Comb. C) & 0.696 & 0.012 & 60.83 \\
\hline
\end{tabular}

- Crude extracts from the growth on sugar cane bagasse, ${ }^{2}$ - Crude extracts from the growth on dirty cotton residue. An: A. niger; En: E. nidulans; Af: A. flavus; Mo: Monilia sp.; Ao: A.oryzae

The release of reducing sugars from pretreated SCB, BS and DCR by crude enzyme samples was measured by DNS and glucose oxidase assays (Figs. 1-6). Figures 1 and 2 indicate that the highest amount of reducing sugars released from DCR occurred after an incubation of $72 \mathrm{~h}$ with the crude extract combination $\mathrm{B}$ of $A$. terreus and $A$. oryzae, followed by the crude extract combination A. In addition, the highest release of reducing sugars after $96 \mathrm{~h}$ of incubation was observed with $T$. longibrachiatum. The glucose concentration decreased significantly after 72 and $96 \mathrm{~h}$ of incubation in comparison to the results shown in Figure 1 (Fig. 2). The release of reducing sugars from SCB increased steadily with the highest concentration detected after $168 \mathrm{~h}$ of incubation (Figs. 3 and 4). It is noteworthy that the release of reducing sugars continued to increase even after $168 \mathrm{~h}$ of incubation (Figs. 3 and 4). The best results for reducing sugar release were achieved with $A$. terreus crude extract alone or in combination A (Fig. 3). The maximal glucose release was detected in mixtures containing A. terreus crude extract alone and in combination C. A similar pattern was observed when BS was used as the substrate (Figs. 5 and 6).

Shapiro-Wilk test demonstrated that all data have normal distribution. ANOVA and Tukey's Pairwise comparisons showed that $\mathrm{P}$ values are less then $5 \%(\mathrm{P}<0.05)$ in almost all the times and substrates used, demonstrating that mixtures have statistical differences among them.
A number of fungi species were found to secrete a group of enzyme activities able to breakdown holocellulose when grown on DCR and SCB. It appears that the activity yield of holocellulose-degrading enzymes is influenced by the agroindustrial residue used as the carbon source. These materials have complex structures composed of different polymers and components that interact with one another in ways that are not fully understood. The biological conversion of these structures requires a consortium of enzymes that interacts synergistically to release products, such as monomers and oligomers, that might serve as fuel precursors and other chemicals. Some isolates, notably A. terreus, produced a significant amount of holocellulose-degrading enzymes. Thus, the mechanism of enzymatic hydrolysis of holocellulose is an important factor to be considered for improving the enzymatic conversion in bioprocesses based on lignocelluloses. Furthermore, the phenomenon of enzyme adsorption should be taken into account when agro-industrial residues are used as substrates.

The mechanism of holocellulose-degrading enzyme adsorption has to do with the presence of highly ordered structures that represent the rate-limiting step in the conversion of holocellulose to soluble products (17). Thus, there appears to be a strong correlation between holocellulose accessibility and the degree of enzyme adsorption. This might contribute to the conversion rates and yields of lignocellulosic structures in plant cell walls (7). 


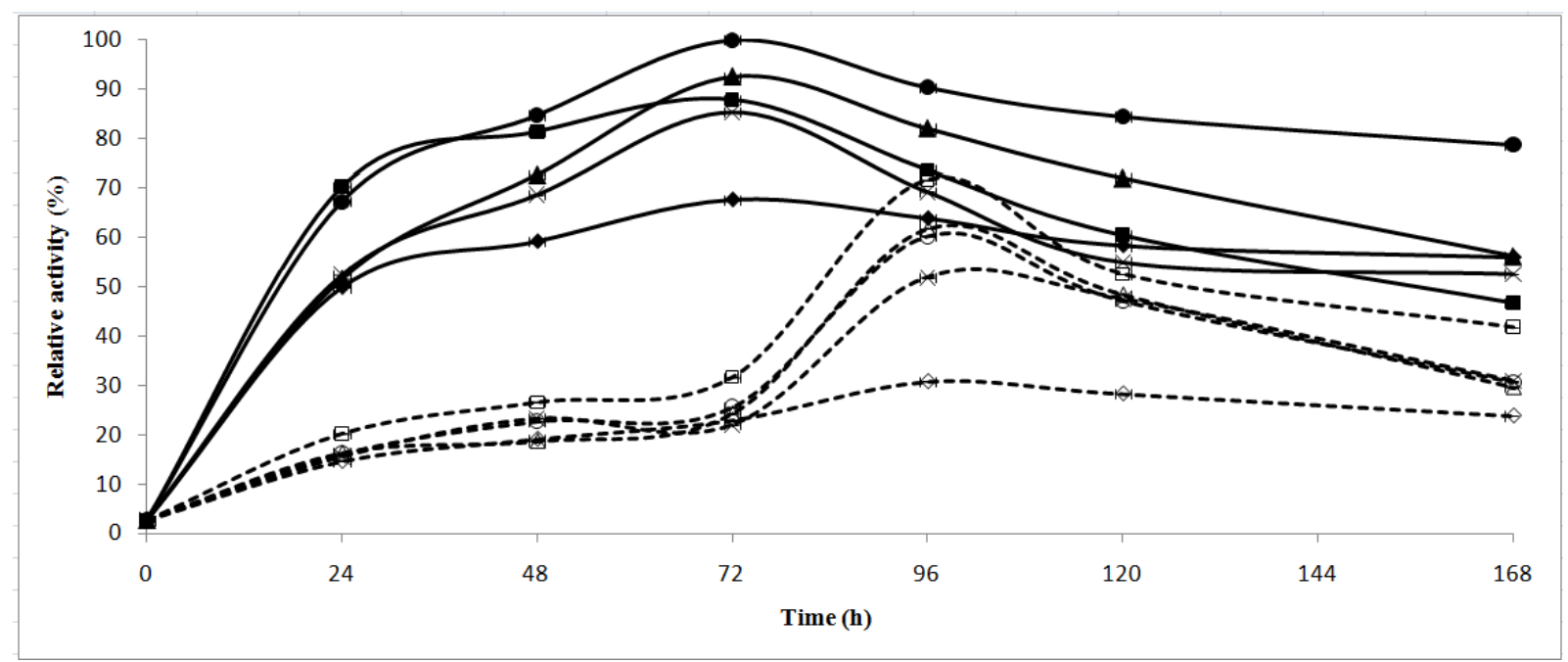

Figure 1. The production of reducing sugars by enzymatic hydrolysis of dirty cotton residue measured by DNS. A. terreus crude

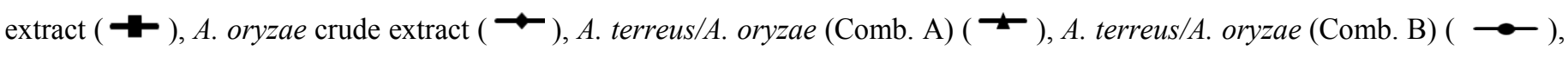
A. terreus/A. oryzae (Comb. C) (-×-), T. longibrachiatum ( $\left.{ }^{-}\right)$, A. niger (->), T. longibrachiatum/A. niger (Comb A.)

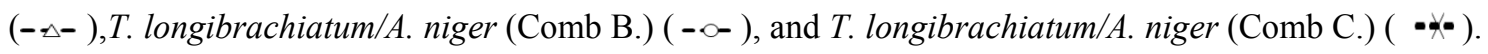

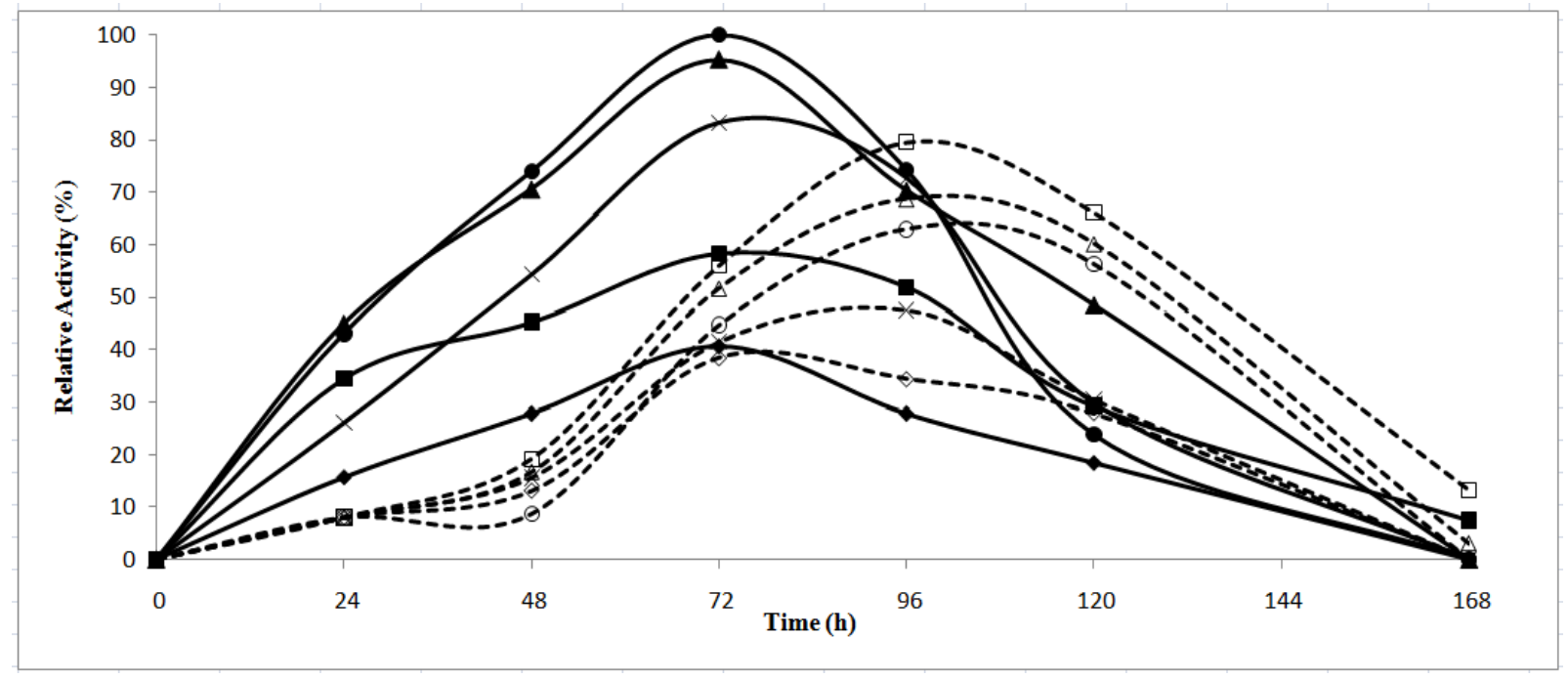

Figure 2. The production of reducing sugars by enzymatic hydrolysis of dirty cotton residue measured by the glucose oxidase method. A. terreus crude extract $(\boldsymbol{-})$, A. oryzae crude extract $(\neg)$, A. terreus/A. oryzae (Comb. A) $(\boldsymbol{\rightarrow})$, A. terreus/A. oryzae (Comb. B) ( $\multimap$ ), A. terreus/A. oryzae (Comb. C) ( $-\times-)$, T. longibrachiatum ( $\bullet$ ), A. niger ( $-\infty)$, T. longibrachiatum/A. niger (Comb A.) (-₫-), T. longibrachiatum/A. niger (Comb B.) ( - - ), and T. longibrachiatum/A. niger (Comb C.) $(\cdot-\not \cdot)$. 


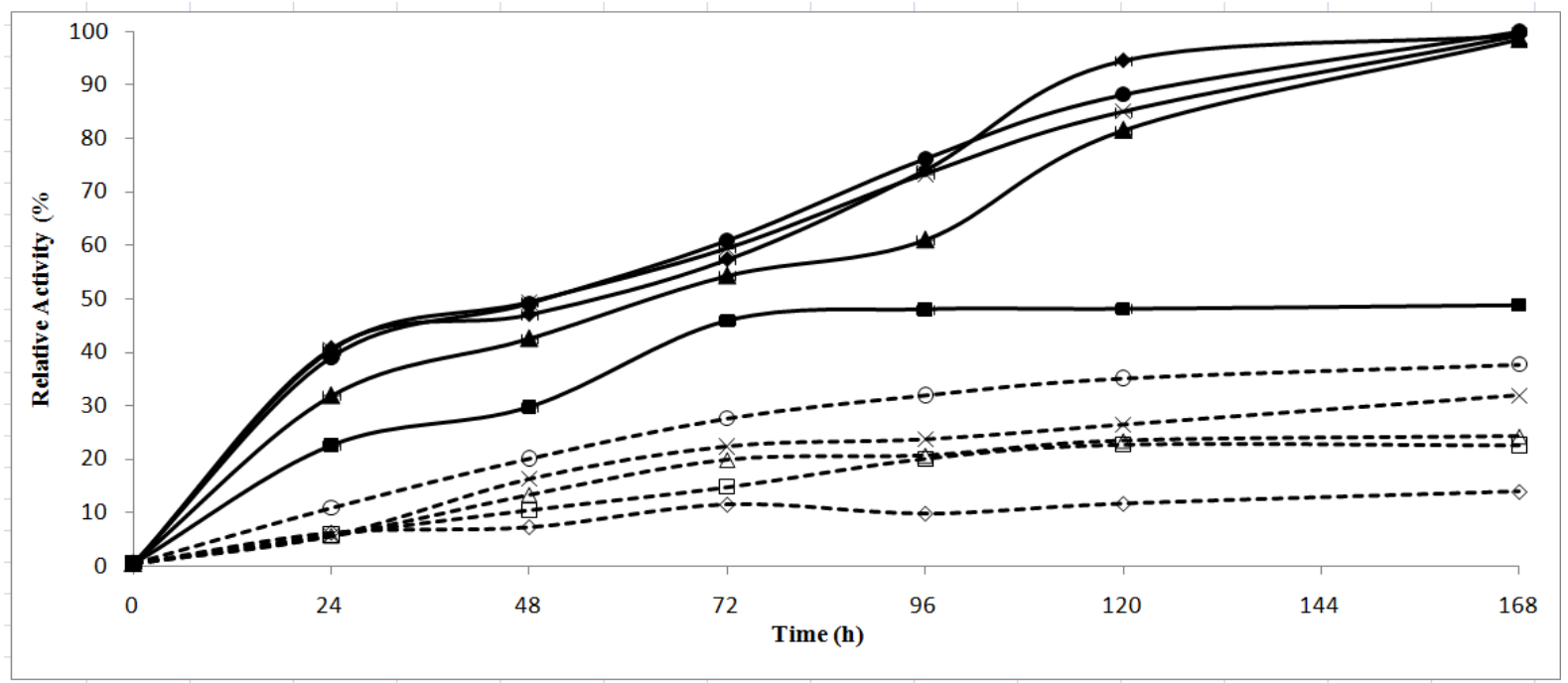

Figure 3. The production of reducing sugars by enzymatic hydrolysis of sugar cane bagasse measured by DNS. A. terreus crude

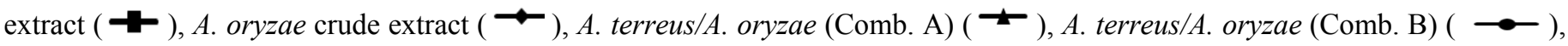

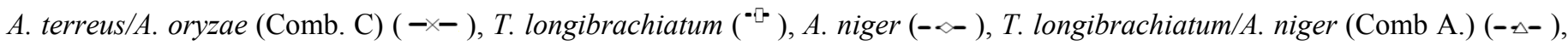
T. longibrachiatum/A. niger (Comb B.) ( - - ), and T. longibrachiatum/A. niger (Comb C.) ( - ‘- ).

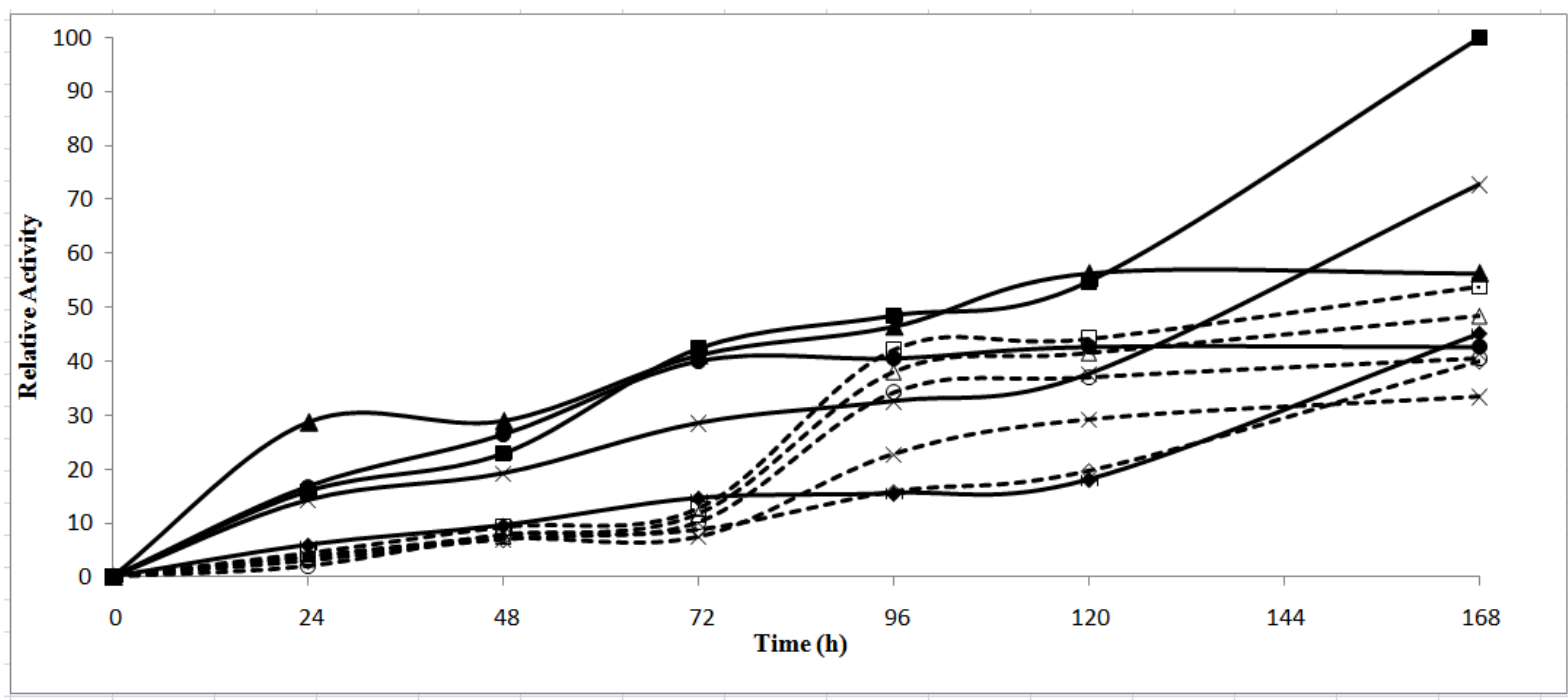

Figure 4. The production of reducing sugars by enzymatic hydrolysis of sugar cane bagasse measured by the glucose oxidase

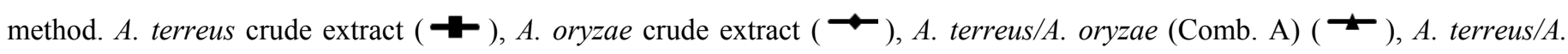

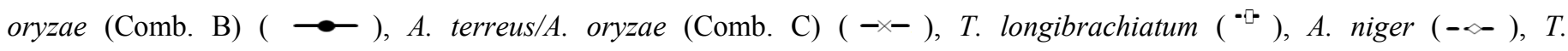
longibrachiatum/A. niger (Comb A.) (-^-), T. longibrachiatum/A. niger (Comb B.) (-- - ), and T. longibrachiatum/A. niger (Comb C.) ( - - - 


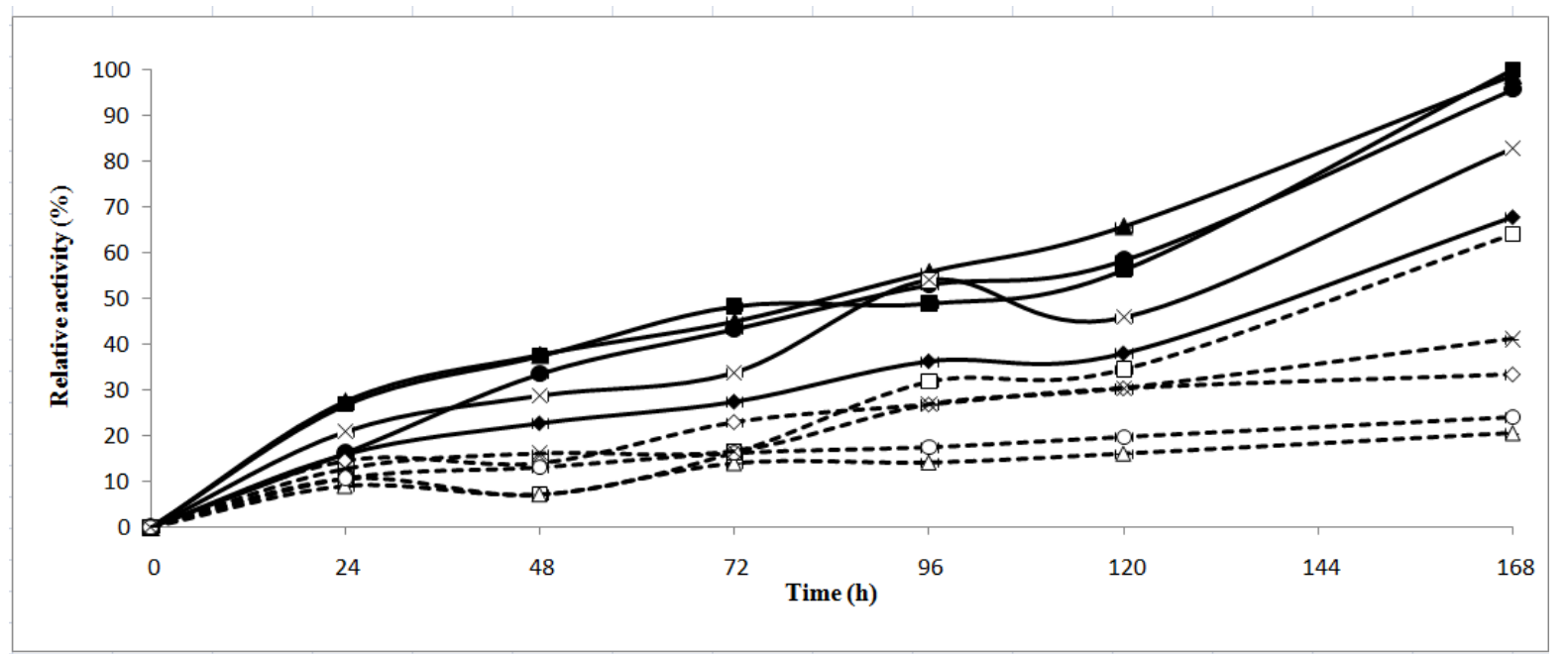

Figure 5. The production of reducing sugars by enzymatic hydrolysis of banana stem by DNS. A. terreus crude extract ( $\boldsymbol{-}$ ), $A$. oryzae crude extract $(\rightarrow)$, A. terreus/A. oryzae (Comb. A) $(\neg)$, A. terreus/A. oryzae (Comb. B) ( $\bullet-)$, A. terreus/A.

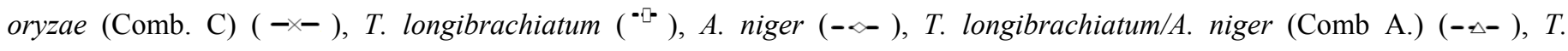
longibrachiatum/A. niger (Comb B.) ( - - ), and T. longibrachiatum/A. niger (Comb C.) ( - - - ) .

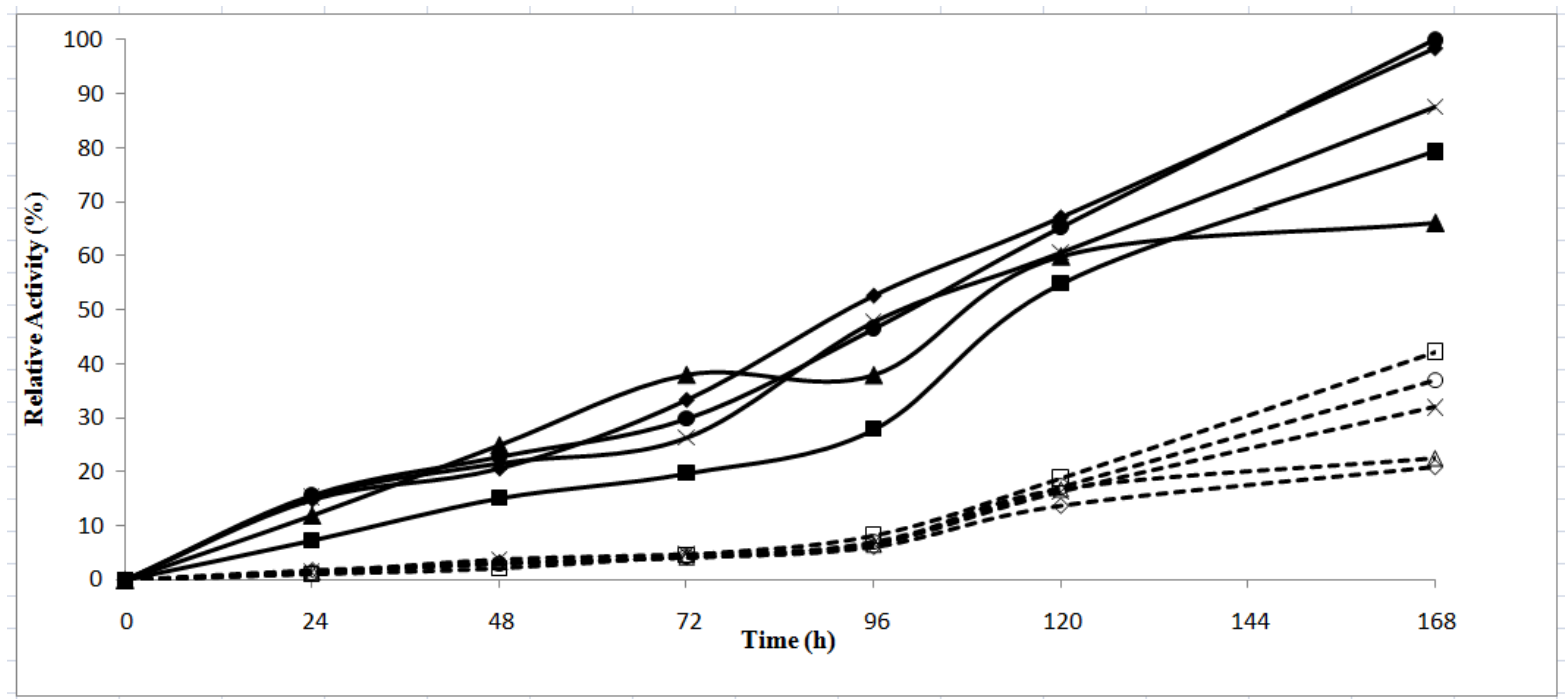

Figure 6. The production of reducing sugars by enzymatic hydrolysis of banana stem measured by the glucose oxidase method. $A$. terreus crude extract $(\boldsymbol{-})$, A. oryzae crude extract $(\underset{\bullet}{\bullet})$, A. terreus/A. oryzae (Comb. A) ( $\rightarrow$ ), A. terreus/A. oryzae (Comb.

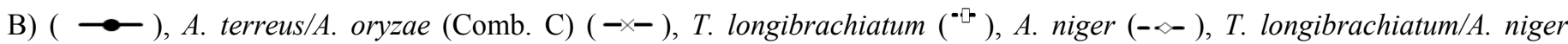

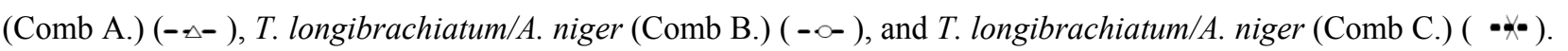


In conclusion, DCR, SCB and BS are inexpensive residues that can be used as substrates to reduce the cost of enzyme production while enzymatically converting the carbohydrate portion of DCR, SCB and BS into fermentable sugars. Further research will be required to study the enzyme mechanisms, particularly the role of xylanases.

\section{ACKNOWLEDGEMENTS}

This work was funded by $\mathrm{CNPq}$ (research grants 563260/2010-6 and 563823/2010-0), National Institute of Science and Technology of Bioethanol and Foundation for Research Support of the Federal District (Brazil, research grants numbers 193.000.470/2008 and 193000584/2009). E.X.F.F. and L.R.S.M. acknowledge the receipt of the research fellowship from the Brazilian National Research Council and research post-graduate maintenance scholarship from CAPES, respectively.

\section{REFERENCES}

1. Andreaus, J.; Filho, E.X.F.; Bon, E.P.S. (2008). Biotechnology of Holocellulose - Degrading Enzymes. In: Hou, C.T.; Shaw, J.R. (eds). Biocatalysis and Bioenergy. Copyright, New Jersey, USA, p. 197-229.

2. Bradford, M.M. (1976). A rapid and sensitive method for the quantitation of microgram quantities of protein utilizing the principle of protein dye binding. Anal. Biochem. 72, 248-254.

3. Dhillon, A.; Gupta, J.K.; Jauhari, B.M.; Khanna, S. (2000). Production of a thermostable alkalitolerant xylanase from Bacillus circulans AB16 grown on wheat straw. J. Ind. Microbiol. Biotechnol. 16 (4), 325-257.

4. Hammer, Ø; Harper, D.A.T.; Ryan, P.D. (2001) Past: Paleontological Statistics Software Package for education and data analysis. Palaeontologia Electronica. [S.I.], 4 (1), 1-9.

5. Kadam, K.L. (2002). Environmental benefits on a life cycle basis of using bagasse-derived ethanol as a gasoline oxygenate in India. Energy Policy. 30, 371-384.
6. Khan, M.A.; Ashraf, S.M.; Malhotra, V.P. (2004). Development and characterization of a wood adhesive using bagasse lignin. Int $J$ Adhesion and Adhesives 24,485-493.

7. Kristensen, J.B.; Felby, C.; Jørgensen, H. (2009.) Yield-determining factors in high-solids enzymatic hydrolysis of lignocelluloses. Biotechnology for Biofuels 2, 1-10.

8. Kumar, R.; Singh, S.; Singh, O.V. (2008). Bioconversion of lignocellulosic biomass: biochemical and molecular properties. $J$ Ind Microbiol Biotechnol. 35, 377-340.

9. Mandels, M.; Andreotti, R.; Roche, C. (1976). Measurement of saccharifying cellulose. Biotechnol Bioeng Sympos. 16, 21-33.

10. Medeiros, R.G.; Coelho, L.A.; Filho, E.X.F. (2008). Agricultural Residues as Source for Production of Hemicellulases from Humicola grisea var. thermoidea. Dynamic Biochemistry, Process Biotechnology and Molecular Biology. 2, 30-33.

11. Miller, G.L. (1959). Use of dinitrosalicylic acid reagent for determination of reducing sugar. Analytical Chemistry. 31, 426-428.

12. Moreira, L.R.S.; Mattos, I.; Monclaro, A.V.; Santos, S.S.T.; Jensen, A.T.; Siqueira, F.G.; Filho, E.X.F. (2008). The use of lignocellulosic substrates as carbon sources for production of xylan-degrading enzymes from Acrophialophora nainiana. Current Topics in Biochemical. 10 (2), $35-45$.

13. Siqueira, F.G.; Siqueira, A.G.; Siqueira, E.G.; Carvalho, M.A.; Peretti, B.M.P.; Jaramillo, P.M.D.; Sposina, S.S.T.; Dias, E.S.; Felix, C.R.; Filho, E.X.F. (2010). Evaluation of holocellulase production by plantdegrading fungi grown on agro-industrial residues. Biodegradation. 21, $815-824$.

14. Siqueira, F.G.; Siqueira, E.G.; Jaramillo, P.M.D.; Silveira, M.H.L.; Andreaus, J.; Couto, F.A.; Batista, L.R.; Filho, E.X.F. (2010). The potential of agro-industrial residues for production of holocellulase from filamentous fungi. Int. Biodeterior. Biodegradation. 64, 20-26.

15. Techapun, C.; Sinsuwongwat, S.; Poosaran, N.; Watanabe, M.; Sasaki, K. (2001). Production of a cellulase-free xylanase from agricultural waste materials by a thermotolerant Streptomyces sp. Biotechnol Lett. 23, 1685-1689.

16. Trinder, P. (1969) Determination of glucose in blood using glucose oxidase with an alternative oxygen acceptor. Ann Clin Biochem. 6, 2425.

17. Zhang, Y.H.P.; Himmel, M.E.; Mielenz, J.R. (2006). Outlook for cellulase improvement: screening and selection strategies. Biotechnol Adv. 24, 452-481. 